\title{
DEVELOPMENT OF A MATERIALS MANAGEMENT STRATEGY TO ENABLE CONTINUOUS WORK FLOW ON-SITE
}

\author{
Cynthia C.Y. Tsao ${ }^{1}$ and Helena Lidelöw ${ }^{2}$
}

\begin{abstract}
When project teams are pressured to limit internal or external Lean coaching due to budgetary concerns, Lean coaches may not have sufficient time to guide project teams in materials management to support milestones. Consequently, while organized project teams will make the time to develop a strategy for managing key materials that impact the critical path, disorganized project teams will more likely manage most materials on an ad-hoc basis. This lack of a materials management strategy then leads to unrealized profits and hidden wastes on projects. As a result, this research seeks to investigate how to develop a basic materials management framework to help project teams begin determining which bulky materials should be: (1) Using a pull system (e.g., through the use of Kanban cards or milk runs) to coordinate deliveries, (2) Kitted off-site vs. on-site, and (3) Organized into prefabricated assemblies. Specifically, this paper will identify various questions, calculations, and artefacts (e.g., equipment for handling and staging materials, signage used to make the materials management strategy transparent to all project participants) that contribute to establishing a comprehensive materials management strategy. In particular, space management emerges as an important tool to organize the flow of materials to match job-site installation rates.
\end{abstract}

Keywords: Materials Management, Space Management, Floor Plan Boards, Procurement, Prefabrication.

\section{INTRODUCTION}

Materials management is critical in helping project teams achieve continuous work flow on-site. By introducing pull-based systems, kitting, and prefabrication to organize material deliveries, project teams introduce standardization and repeatability into the design of their project's production system. This reduces the likelihood of work variation errors and allows workers a chance to gain learning curve benefits, thus yielding improvements in installation quality and productivity.

Discussions over the years have debated if prefabrication is "better" than on-site construction in one way or another and if it leads to higher quality or faster completion (e.g., Bekdik et al. 2016). Even though these are interesting arguments, the reality

1 Director of Lean Strategy, Consigli Construction Co., Inc., Boston, MA, USA, ctsao@consigli.com and Owner, Navilean, Brookline, MA, USA, research@navilean.com.

2 Associate Professor, Div. of Industrialized and Sustainable Construction, Dept. of Civil, Environmental, and Natural Resources Engineering, Luleå University of Technology, helena.lidelow@ltu.se 
evidences that on-site work and prefabrication can yield mixed results due to a variety of factors that may or may not be within the control of project teams. In addition, project materials sit on a spectrum of off-site to on-site work processes, and a project's product design can limit the production strategies that materials vendors may need to use for the specified materials (Figure 1). For instance, if an architect developed a building's envelope to consist primarily of stick-built elements, building envelope trade partners that advocate for prefabrication will need to advocate for a re-design of the building envelope if they want to propose that the project consider using unitized assemblies instead within the building envelope. Furthermore, while vendors will use different production strategies (e.g., engineer-to-order, make-to-stock) for the materials that they supply to construction projects, they may also need to adjust those strategies due to a number of other factors, both internally- (e.g., the types of equipment owned by the company, current employee skill set) and externally-driven (e.g., relationships with their suppliers, services and products offered by their competitors).

Then, from the perspective of production system design, the spectrum of off-site to on-site work processes may require different work structuring approaches in terms of sequencing, work handoffs, decision-making, and coordination (Tsao et al. 2004). Due to these inherent differences in the respective production and delivery systems (e.g., Ballard and Howell 1998), a conflict may emerge in the production strategies for materials that need to be installed on projects.
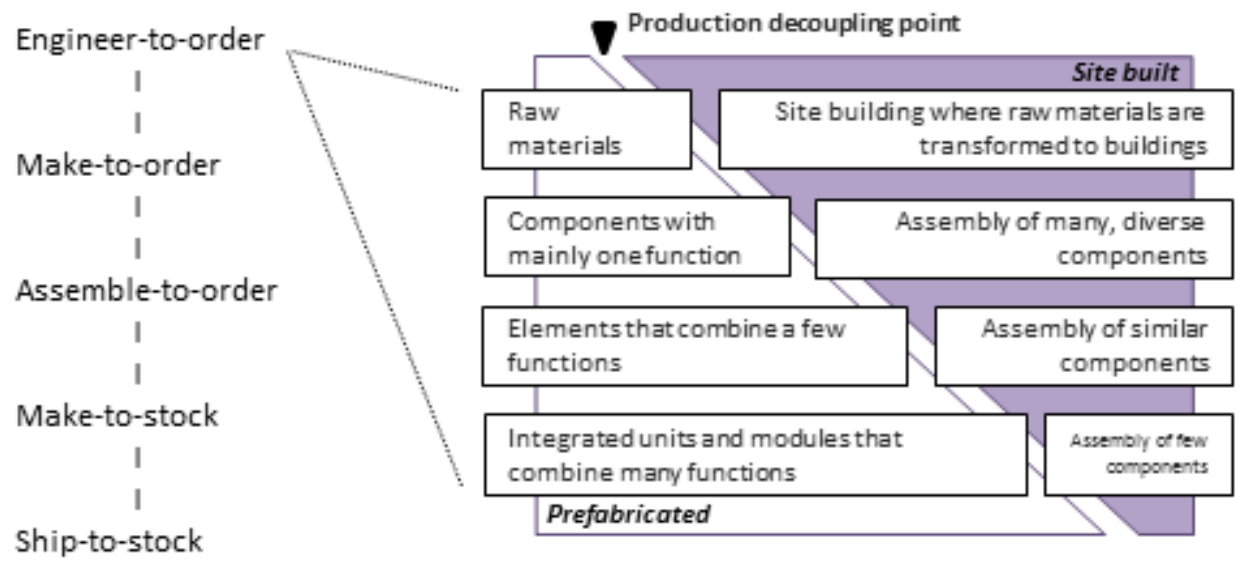

Figure 1: Spectrum of Off-Site to On-Site-Built Work Processes

(e.g. Lidelöw and Olofsson, 2016)

Planning for prefabrication means knowing in advance the size, arrival and use rates, and quality of goods. Then, a challenge that is often over-looked is the space the arriving prefabricated assemblies take up on the building site. Similarly, any activities needed to prepare or kit materials also need designated spaces and, at times, special tools and equipment. On-site activities may also compete for these same resources of space, tools, and equipment. Thus, there is a need for understanding production system design and planning when mixing prefabricated assemblies with on-site work, and this line of thinking has many predecessors such as Arbulu and Ballard (2004), Bekdik et al. (2016), and Pasquire et al. (2005).

The long-term aim of this research effort is to help project teams determine (within the spectrum of off-site fabrication to on-site installation) the best materials management strategy for major project elements. The goal of this paper is to begin identifying a framework, method, and tool set that will help project teams (both experienced and 
inexperienced in LPS implementation) understand and manage the flow of incoming materials, its placement, its changing stages over time, and couple this to the work flow. Thus, this particular study aims at describing the basic building blocks for a materials management strategy that supports the spectrum of off-site to on-site work.

\section{Methodology}

We began this research effort by organizing various factors that are considered in the planning and purchasing of project materials into a spreadsheet to assist with data collection and analysis. Then, we distributed this spreadsheet to multiple project teams to get some initial feedback but we got a very limited response. As a result, we adjusted our methodology to test the spreadsheet with one project as the first case study and then refine it for testing on the next case study. This approach was not only easier to sustain, it reinforced the spirit of continuous improvement for developing, testing, and refining the framework for a materials management strategy.

Our first case study involved a hospital renovation project in the U.S. On this project, the construction manager / general contractor (CM/GC) not only self-performed some trade specialties but also managed the order and delivery of select materials for a few trade partners. This was necessary because this project involved renovating only one floor at a time within one of the hospital's buildings, and the hospital wanted to minimize disruption by the construction project to healthcare providers, patients, caregivers, and hospital operations in adjacent areas and floors.

As a result, before this research team got involved in the project, the $\mathrm{CM} / \mathrm{GC}$ project team had already developed a comprehensive materials management strategy that was driven more by logistical challenges as opposed to budgetary concerns. The materials management strategy in place had used various lean techniques, including kitting, development of off-site assemblies, and pull-based material deliveries to limit job site clutter from excess materials and packaging. Because of these developments, the research team used this project as a case study for developing the initial framework for materials management planning. Then, using that same framework, we could help the project team determine how to best manage materials in the next phase of the project.

We began by asking the project team to identify the top ten bulkiest items that they coordinated for the project. Then, we developed the initial draft of the materials spreadsheet to clarify the various parameters that influenced the order, delivery, staging, and installation of these bulky items for the recently completed floor.

During data collection, several questions came back repeatedly: Is it better for the project team to purchase prefabricated assemblies from a third party or should the $\mathrm{CM} / \mathrm{GC}$ organize a field factory to form separately-procured materials into subassemblies before final installation? Where should any staging of materials take place on- or off-site? If off-site, how close should that off-site location be in relation to the project? What is the lot size in each delivery and how should materials be handled (on pallets, one piece, etc.)? From these questions combined with the knowledge gathered from earlier research in production system design, we started developing an understanding of the basic ingredients that are needed in a planning tool to support the development of a materials management strategy. Thus, our revised spreadsheet represents the first draft of such a planning tool that builds on developments in space scheduling, extending the work of Choo and Tommelein (1999), Frandson and Tommelein (2014), and Cheng and Kumar (2015). 
The questions listed above also revealed the need for a daily check-in tool that makes transparent the status of materials delivery, staging, and installation on the job site. Thus, based on the lessons learned from our first case study and our experience on recent projects, we will also discuss a prototype method for materials management to help implement whatever materials management strategy is developed with the planning tool and prevent construction workers from spending much of their work time searching for and handling materials instead of doing value-adding work. This line of thinking aligns with Mossman (2007) who called for a new discipline within Lean Logistics.

Next, the following sections will describe in detail facets of the planning tool that have emerged from the revised spreadsheet as well as a prototype method for daily materials management that we seek to test in future research.

\section{SpreadsheEt For Materials MANAgEMENT PlanNing}

Table 1 is an excerpt from the revised spreadsheet that we used on the hospital renovation project. It contains some headers that we used to analyze each bulky material, and we included one of the more challenging material components - vinyl wall protection - to illustrate how the spreadsheet helped the project team review the lessons learned from the recently completed floor and then revise their procurement, delivery, handling, staging, and installation processes for that same material on the current and future floors of the renovation project. For example, on the recently completed floor, the project team submitted kitting orders to an off-site materials storage facility to arrange and deliver to the job site kits of 4' x 10' sheets of wall protection consisting of varying colors. Then, carpenters would make at least two cuts on the job site to match the sizes needed within the patient rooms and corridors. For the current and future floors, the $\mathrm{CM} / \mathrm{GC}$ decided to ask the wall protection fabricator to complete the first cut for all pieces. Then, carpenters would only need to complete the second cut on site.

\section{Prototype Method For DAILy MATERIALs MANAGEMENT}

The materials management spreadsheet examines two critical parameters in job site planning: the space occupied by a material and the time when this space is needed. These are issues that are addressed by space scheduling, and a BIM model can help simulate the occurrence of activities and the space they occupy over time (Frandson and Tommelein 2014). Past research efforts have also worked on combining the BIM model with a schedule using automation (e.g., Cheng and Kumar 2015).

We intentionally make a distinction between storage and staging materials for the following reasons:

- Storage - On previous projects, we have heard lean coaches declare, "The most expensive statement on the job site is 'Just put it over there for now."' Materials not delivered just-in-time (JIT) may be stored on-site indefinitely and moved multiple times before installation.

- Staging - Staged materials do not need to be handled a second time before installation. Ideally, materials are delivered JIT, which can be better translated from Japanese as "at the right time." 
Table 1: Excerpt from the Materials Management Spreadsheet for a Sample Bulky Material (** indicates follow-up items for the project team)

\begin{tabular}{|c|c|}
\hline Material Component & 4' x 10' Wall Protection (WP) pieces \\
\hline Color Variation & $\begin{array}{c}4 \text { colors in Patient Room A; } 4 \text { colors in Patient Room B; } 3 \\
\text { colors in corridors }\end{array}$ \\
\hline Size Variation & 12-14 sizes amongst the 4 colors in each patient room \\
\hline $\begin{array}{l}\text { \# of Material Pieces Needed for } \\
\text { each Unit }\end{array}$ & $\begin{array}{l}13 \text { sheets }\left(4^{\prime} \times 10^{\prime}\right) \text { needed for Room Type A; } 9 \text { sheets }\left(4^{\prime} \times\right. \\
\left.10^{\prime}\right)+1 \text { strip }\left(6^{\prime \prime}\right) \text { needed for Room Type B }\end{array}$ \\
\hline Number of Units & 5 Room A and 15 Room B; \# Corridors TBD \\
\hline Total \# Material Pieces Needed & $\begin{array}{c}100 \text { sheets for patient rooms; }{ }^{* *} \text { TBD \# of pieces for } \\
\text { corridors }\end{array}$ \\
\hline $\begin{array}{l}\text { Procurement Rate and Delivery } \\
\text { Condition to Off-Site Location }\end{array}$ & $\begin{array}{l}\text { Once all WP has been released for fabrication, fabricator } \\
\text { will deliver large crates containing mixed colors and sizes }\end{array}$ \\
\hline $\begin{array}{l}\text { Off-Site Location Material } \\
\text { Processing }\end{array}$ & $\begin{array}{l}\text { Unpack from large crates from fabricator; }{ }^{* *} \text { fill smaller } \\
\text { shipping crates (no need to sort according to color) }\end{array}$ \\
\hline $\begin{array}{l}\text { Delivery Truck Condition and } \\
\text { Rate to the Job Site (\# pallets, } \\
\text { carts, or crates per delivery) }\end{array}$ & $\begin{array}{l}\text { Transport smaller shipping crates that contain up to } 20 \\
\text { sheets each to job site; } 3 \text { trips for } 100 \text { sheets in patient } \\
\text { rooms; } \sim 3 \text { trips for corridors }\end{array}$ \\
\hline $\begin{array}{l}\text { On-Site Location Material } \\
\text { Processing }\end{array}$ & $\begin{array}{l}\text { Unpack from smaller shipping crates at Loading Dock and } \\
\text { sort according to height and color into } 2 \text { site-crates }(4 ' \mathrm{H} x \\
\left.10^{\prime} \mathrm{L} \times 1 \text { ' } \mathrm{W}\right) \text { before elevator; Bend to fit into elevator } \\
{ }^{* *} \text { How many within each site-crate and still fit within } \\
\text { elevator? }\end{array}$ \\
\hline $\begin{array}{l}\text { Union Rules for Materials } \\
\quad \text { Management? }\end{array}$ & $\begin{array}{c}\text { Carpenters needs to distribute WP because it is a finish } \\
\text { material }\end{array}$ \\
\hline Staging Condition & $\begin{array}{l}\text { Keep } 2 \text { site-crates in the Equipment Storage Room; ** Sort } \\
\text { WP according to color and size within the site-crates so } \\
\text { carpenters can pull from the middle of the WP stack }\end{array}$ \\
\hline Equipment needed for Installation & $\begin{array}{l}{ }^{* *} \text { 2nd site-crate and } 4{ }^{\prime} \times 8 \text { 8 plywood table with jig for } \\
\text { carpenters to make second width cut in WP using razors }\end{array}$ \\
\hline $\begin{array}{l}\text { Space needed for Staging / } \\
\text { Installation }\end{array}$ & $\begin{array}{l}{ }^{* *} \text { Project team to determine if Loading Dock has enough } \\
\text { space to sort WP from shipping crates into site-crates; } \\
\text { Wall spaces in patient rooms + corridors for installation }\end{array}$ \\
\hline $\begin{array}{l}\text { Labor needed for Staging / } \\
\text { Installation }\end{array}$ & $\begin{array}{l}3 \text { carpenters to transport }+ \text { stage material on previous } \\
\text { floor; Typically } 2 \text { carpenters to install each piece }\end{array}$ \\
\hline Installation Rate & $\begin{array}{c}2 \text { weeks for North side patient rooms; } 2 \text { weeks for South } \\
\text { side patient rooms }\end{array}$ \\
\hline
\end{tabular}


Project teams should strive to avoid the storage step on-site because this will tie up critical work space. However, if storage is unavoidable, then it would be helpful to clarify where and when materials are "stored" vs. "staged."

Space planning requires project teams to track not only installation activities that are normally accounted for in traditional project schedules, but also the space required during delivery, storage, and staging of the materials and equipment required to support final installation (Figure 2). Thus, the materials management spreadsheet is intentionally structured to help tease out the various parameters that should be considered during space planning to assist project teams with accounting for the various resources required during delivery, storage, staging, and installation while designing and organizing the project's production system.
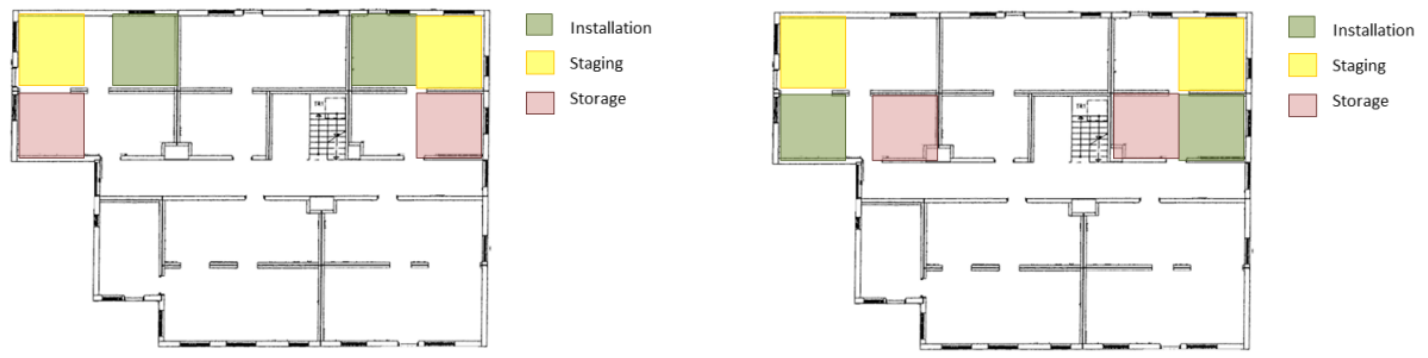

Figure 2: Mock-up of Space Planning for Storage, Staging, and Installation on Day 1 and Day 3

When a building site is small, there might not be enough room for staging materials near final installation locations. The project team would then have to store materials in another location and coordinate workers with equipment to move those materials from the storage location to the staging and installation locations. In these situations, the project team should evaluate whether this extra materials handling should be regarded as wasteful or necessary. If there are ways to organize the materials into prefabricated assemblies, then this extra materials handling can be considered primarily wasteful.

However, if the product design and site logistics prevent the ability of trade partners to form prefabricated assemblies, then this extra materials handling might be considered necessary but wasteful. Furthermore, the additional costs for handling, storage, and staging prefabricated assemblies may exceed the production gains from streamlined installation processes, so the project team may decide prefabrication is not worth the effort in such a situation. In the worst case, project teams with limited prefabrication experience may store / stage and re-store / re-stage the prefabricated assemblies around the job site several times because they occupy space required for other activities. Each re-handling represents a cost, and thus the gain with prefabrication diminishes with each re-handling of the assemblies.

To improve materials management visualization, project teams can use posted floor plans to track the storage, staging, and installation of materials and prefabricated assemblies throughout the job site. Then, by generating a series of floor plans that represent materials management over time, project teams can more easily integrate materials management discussion into on-site daily huddle meetings (Figure 2).

Ideally, as mentioned at the beginning of this section, project teams have resources available to enter the details of materials storage, staging, and installation within their projects' 4D-BIM models. Then, project teams can easily generate the posted floor plans by printing out select views of their building models. On projects that do not have such resources, project teams could instead, for example, use one of the following approaches 
to manually generate posted floor plans: (1) using permanent marker or black graphic chart tape on whiteboards (Figure 3), (2) printing floor plans on mounted foam board with whiteboard lamination, (3) placing printed floor plans under acrylic sheets on a table, or (4) attaching printed floor plans onto walls using adhesive material.
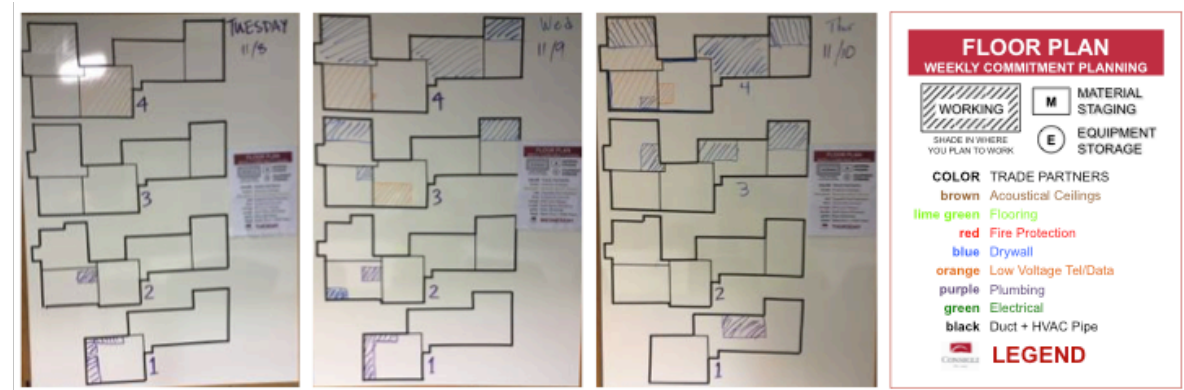

Figure 3: Floor Plan Boards used for Weekly Commitment Planning and Materials Management on an Office Renovation Project

These manual approaches enable meeting participants to discuss and quickly consider different strategies for materials management in real-time during on-site daily huddles. As a result, the posted floor plans have the potential to become a close representation of the actual status of key materials and prefabricated assemblies on the building site. If they get key foremen to regularly use this prototype method to collaborate on materials management, project teams will then become more capable of proactively managing the material flow and supply chain for the building site (Mossman 2007).

\section{FUTURE RESEARCH AND CONCLUSIONS}

The next research steps involve: (1) refining the spreadsheet for materials management planning through the analysis of additional materials, (2) identifying reasons why project teams should manage materials using kitting, prefabricated assemblies, or pull to coordinate deliveries, and (3) trying various manual approaches of posted floor plans to determine which are easier to manage in real-time.

Then, the next phase of research may involve: (4) examining how to set up guidelines on which materials to include in a materials management effort, (5) establishing project conditions that represent different levels of effectiveness in materials management, and (6) comparing the timing, frequency, and duration required of a 4D-BIM approach to materials management vs. a manual approach to attain these different levels of materials management effectiveness. Additional future research efforts may also involve: (7) testing IT tools that can assist with representing the actual status of key materials and prefabricated assemblies and (8) investigating how accurate of a representation of the actual status of key materials and prefabricated assemblies is needed for the different levels of materials management effectiveness.

As this research is in its infancy, limited conclusions include: (1) materials management efforts should first focus on bulky, difficult to manage items as identified by project teams, (2) a simpler approach for planning and statusing materials improves the likelihood that project teams can become proactive in materials management, (3) multiple work sessions with project teams provides opportunities for critical parameters that should be considered in materials management to emerge, and (4) discussions with workers directly involved in materials management in earlier project phases are critical for clarifying lessons learned and getting feedback on ideas for future project phases. 
Material elements go through different stages of transformation as they are fabricated from raw materials and handled off-site and then delivered, stored, staged, and installed on a building site. Thus, by testing the spreadsheet for materials management planning and the prototype method for daily materials management, this research is contributing to the development and refinement of tools that support the Transformation-Flow-Value Generation (TFV) theory of production (Koskela 2000).

\section{ACKNOWLEDGEMENTS}

We wish to acknowledge the efforts of Brian Hamilton, Ricky Gala, Sean Dillon, and Dave Deters of Consigli Construction Co., Inc. in developing and implementing the materials management strategy used on this project before the research team's involvement. Then, we would like to thank Sam Giard for assisting us in testing this research effort's Materials Management Spreadsheet for refining the materials management strategy. Thanks also to Mike Collins, Rich Bedard, and Steve Tarckini for providing feedback on material handling and installation techniques.

\section{REFERENCES}

Arbulu, R., and Ballard, G. (2004). "Lean Supply Systems in Construction." IGLC-12 Proceedings, Helsingør, Denmark, 3-5 Aug.

Ballard, G. (2000). The LPS of Production Control. Ph.D. thesis, Univ. of Birmingham.

Ballard G., and Howell G. (1998). "What Kind of Production is Construction?" IGLC-6 Proceedings, Guarujá, Brazil, 13-15 Aug.

Bekdik, B., Hall, D., and Aslesen S. (2016). "Off-Site Prefabrication: What Does it Require from the Trade Contractor?" IGLC-24 Proc., Boston, USA, 20-22 Jul.

Cheng, J.C.P., and Kumar, S. (2015). "A BIM-based Framework for Material Logistics Planning.” IGLC-23 Proceedings, Perth, Australia, 29-31 Jul.

Choo, H.J., and Tommelein, I.D. (1999). "Space Scheduling using Flow Analysis." IGLC-7 Proceedings, Berkeley, USA, 26-28 Jul.

Frandson, A. G., and Tommelein, I.D. (2014). "Automatic Generation of a Daily Space Schedule.” IGLC-22 Proceedings, Oslo, Norway, 25-27 Jun.

Koskela, L. (2000). An Exploration toward a Production Theory and its Application to Construction. Ph.D. thesis, VTT Building Technology, Espoo, Finland, 296 pp.

Lidelöw, H., and Olofsson, T. (2016). "The Structure and Predefinition of the Industrialized Construction Value Chain.” In proceedings from the Int'l. Conf on Construction and Real Estate Mgmt., ICCREM, Oct 2016, Edmonton, Canada.

Mossman, A. (2007). "Lean Logistics: Helping to Create Value by Bringing People, Information, Plant, Equipment and Materials Together at the Workface." IGLC-15 Proceedings, East Lansing, Michigan, USA, 18-20 Jul.

Pasquire, C., Gibb, A., and Blismas, N. (2005). "What Should You Really Measure if You Want to Compare Prefabrication with Traditional Construction?" IGLC-13 Proceedings, Sydney, Australia, 19-21 Jul.

Tsao, C.C.Y., Tommelein, I.D., Swanlund, E., and Howell, G. (2004). "Work Structuring to Achieve Integrated Product-Process Design." ASCE, J of Constr. Engrg. And Mgmt, Nov/Dec, 130(6), 780-789. 